\title{
Impact of Climate Change on the Fishermen's Livelihood Development: a case study of village in Coromandel Coast
}

\author{
Shanmugarajah Srikanthan \\ Ph.D. Scholar, Puducherry Institute of Linguistics and Culture, Puducherry, India
}

\begin{abstract}
This study analyzes the impact of climate change on fishermen livelihood development. Climate change is defined a change in the statistical properties of the climate system in particular region when considered over long periods of time, regardless of cause. However it is classified into two categories namely predictable and unpredictable climate change based on the discussion with village dwellers. In this paper, those climate change or weather condition that may occur in coming times could be predicated in advance is defined as predictable climate changes for example cyclone and those climate change or weather condition could not be predictable in advance is defined as unpredictable climate changes for example changing water current. This study focuses on the impact of unpredictable climate change on the fishermen livelihood development. It has gained a few attentions from the social science researches.

The data for this study were collected through informant case studies from fishing village of Pommaiyar Palaiyam located in Coromandel Coast, Tamil Nadu, India during the intensive fieldwork period of doctoral research, and the qualitative approaches are used for analyzing the data. The finding of this study explores the correlation between the unpredictable climate change and multi-dimensional paradigm of poverty of the proposed study village as follows: (1) the climate change of the village from the last two years, (2) the impact of unpredictable climate change on fishermen livelihood development activities: occupation uncertainty, income disorganization, damages, loses of fishing equipments and psycho-social problems, and (3) the suggestions and recommendations from this issue. This study analyzed their social problem especially multidimensional poverty with the concept of vicious circle which is a key factor for their prolonged poverty and psycho-social problem which is a barrier for livelihood development activities uplifting of this village and suggests that the measures to be taken to reduce the present scenario of the people.
\end{abstract}

Keywords: Livelihood development, unpredictable climate change, Poverty, Natural disaster Indian Coromandel Coast.

Submitted Date 22 June 2013

Accepted Date: 27 June 2013

I. Background And Objectives Of This Study

India, a developing country is a "Peninsula" surrounded by the Indian Ocean and the Himalayas. The climate condition of Indian sub-continent is mostly determined by the monsoon because of the east and west sides of India are respectively covered by the seashore called Bay of Bengal and Arabian Sea. The geographical location of the country has made the people very much depended on the environment and vulnerable to natural disasters. When the climate change aggravates, those who are living in rural areas, get affected seriously. Rural livelihood of India is highly dependent on the natural resources which are dependent on the nature and climatic conditions.

The life of human including other animals is influenced by their surrounding biotic and abiotic environment called socio-cultural environment. Many anthropologists view that human culture which means 'ways of life' is usually the consequence of the interaction between man and nature. That is to say that way of food productions, habits, dressing patterns, religious beliefs and rituals are moulded by their surroundings environmental features. In livelihood activities, the physical environments like lands shape, water resources are considered as major determining factors in general and climate condition is a prominent in particular.

India is essentially "a nation of villages" and nearly 70 per cent of total population of India living in villages [1]. The Indian economy is built upon the village economical sectors. It should be mentioned that Mahatma Gandhi also revealed this kind of thoughts. At the same time, the economic activity of village dwellers of India is related to its environment. And also Indian annual major budget income depends on these villages economic activities. In this situation, climate change is a major challenge of village's livelihood activities in India and is viewed the causes for the many social problems particularly multi-dimensional poverty.

Fishery has been the oldest and most important livelihood option for the inhabitants of coastal India, since times immemorial. Besides the marine environment, it has considerably contributed to the livelihood security of the coastal populace. The life of the coastal community centered around the coastal zone. Though a 
festival, marriage functions or even death, the community is closely related to the natural marine resource.

About 1 per cent of Indian's Population depends upon the fishery sector as a primary source of livelihood which provides direct employment to about 6 million fisher men and women and to another 6 million people who are employed in fishery related activities. The contribution of the fisheries to Gross Domestic Product (GDP) is about 1.3 percent [2].

Fishing is an important economical sector in the South Asian region along with agriculture practice. Both sectors are being mostly undergone into the vulnerability due to climate change. The consequences of climate change is directly or indirectly affecting people who are solely dependent on the livelihood occupation "fishing" is facing lot of multi-dimensional and socio-economic problems. Under this climate changing scenario, objective of this study will be discussed the problems faced by fishing community for their livelihood development regarding the climate change. In this context, a survey has been conducted to assess the relationship between the impact of unpredictable climate change and multi-dimensional poverty in a Coromandel coastal fishing village namely Pommaiyar Palaiyam of Tamilnadu, India.

It should be noteworthy that fishing is one of the most vulnerable sectors to be affected by the unpredictable climate change. Despite the technological advance in the $20^{\text {th }}$ century, weather and climate are still key factors in determining fishing production in the most areas of South Asia. Changing patterns of warming, rain fall and wind are major variables to determine the productivity of fish and their relationship are not simply linear. The 400-odd kilometers of sandy beaches that make up Tamilnadu's Coromandel Coast are surf-beaten and dotted with a string of approximately 230 fishing hamlets. These fishers rely on adjacent fish resources that are made up of many species [3]. These village dwellers are frequently affected by unpredictable climate change along with predicable climate change such as cyclone. In this background if this problem is not addressed adequately, it could seriously hinder sustainable livelihood development and poverty eradication efforts in this region.

\section{Study Area}

The study area, Pommaiyar Palaiyam being one of the fishing villages around $1.5 \mathrm{~km}$ shoreline is situated on the Coromandel coast of Tamil Nadu, India. Even though there are indeed three major caste groups are living in Pommaiyar Palaiyam village council where the fishermen community functions as a separate unit by organizing village Panchayam which literary means a traditional community organization. The total families of this village lived in seashore before the tsunami had attacked, 2004. At present, many village dwellers have resettled in nearest place that is long far $1.5 \mathrm{~km}$ from the old village allotted by the Government of India.

However, a number of families are desirous to live at seashores because of two reasons. One is people who are living in seashore felt that the distinction of new village to seashore is long far and second is the house built by organization should be repaired. If they move to new house they should spend a lot of money, nearly 2 lakhs in Indian rupees.

It should be noted that this village is one of the erosive villages in the Coromandel coast. 6 months of fieldwork teaches the nature of erosion in this village. It is also seemed as one of the major challenges for their fishing activities.

\section{Methodology}

Both environmental anthropology and environmental sociology have emerged as subfields within their respective disciplines to address the role of environment from both social and cultural aspects. There are a number of methods associated with qualitative and quantitative in these fields to analyze the relationship between the social problems and climate change. However, the present study is only based on 'case study' that is one of the techniques in the qualitative approaches. Indeed, a case study is an intensive approach. A researcher focuses on only one specific instance of the phenomenon to be studied through this approach [4]. In this follows, the study concentrates the one of the social problems which is as a consequence of the unpredictable climate change on the village dwellers livelihood development namely poverty.

The data for this study were collected through informant case study during the period of fieldwork for the doctoral program. The fieldwork was initiated at August, 2012 and it covers nearly 6 month. After frequent visits of the village, the researcher made discussion with the village dwellers, which could able record some social issues, particularly the consequence of unpredictable climate change related to poverty. It should be noted here that 20 informants were selected as purposive sample population and inquired for this study. Out of 20 informants, 60 per cent was fishing labourers, another 30 per cent was small boat owners who used traditional equipments for fishing and only 10 per cent of informants were selected from the engine boat owners. Apart from this, the researcher also behaves as a participant observer in this field. It helped to realize the contemporary problems faced by fishermen due to this unpredictable climate change.

During the daily visit to the field area for data collection in the early morning, the feelings of the fishermen who come back from the sea could be realized. Some time they talked very happily and the other 
time they expressed their sadness. It depends on the scale of fish netted by them. There are some questions arisen through the conversation with fisherfolk: what are the factors behind this imbalance in the fishing activities? That is, how they can catch lot of fishes on some time and why they are returning with empty boat the other time..! such way they shared lot of information which are mostly related to the unpredictable climate change, that helped to analyze their multi-dimensional poverty.

\section{Result And Discussion}

Impact of climate change on the human life has been continuing since the origin of the human beings in the world. However the dimension of the climate change on the human life varies from time to time. At present it is one of the most significant challenges to global economic development as well as village dwellers' livelihood development. During the last fifty years, many countries have felt its effects in all sectors. There are many studies to estimate the effects if climate change on the village life forwarded by many researches. Hence, most of them brought out the impact of predictable climate change on the human life and its related problems for example soil, water, farming, human health. This study explores the impact of unpredictable climate change in the livelihood developmental activities. Especially, it focuses artisanal fishing community.

Fishing is a human activity and work as an interface between human society and sea. Climate change has a multi-dimensional effect on human activities. Of these, fishing is prone to be the most affected because the important determining variables, that temperature and wind are mainly climate related. When it suddenly undergoes into radical change, the productivity of fish is also affected. In this following, the impact of unpredictable climate change has emerged as an important phenomenon in the human livelihood development researches.

\subsection{Nature of Climate change}

The Coromandel coast of Tamilnadu, India has been faced episode of tragedy experiences in relation with environmental disasters such as tsunami, cyclone and frequent changes of monsoon pattern which are the results of climate change. In particular, fishing communities of this region are being mostly affected by this disasters leads to profit lose, equipment damages as well as heavy impact on the day to day life of human beings.

Climate change is defined a change in the statistical properties of the climate system in particular region when considered over long periods of time, regardless of cause. Beside according to the Intergovernmental Panel on Climate Change (IPCC), climate change refers to any change in climate over time, whether due to natural variability or as a result of human activity [5]. However, according to the survey from the study area, this study classified climate changes into two sub-categories: predictable climate change such as cyclone, storm, heavy rain and unpredictable climate change such as nature of wave, wind, and water current. In this paper, the researcher defined that those climate change or weather conditions that may occur in coming future times could be predicated in advance as predictable climate change for example cyclone and those climate changes or weather condition could not predict in advance as unpredictable climate change for example changing water current. However, the impact of unpredictable climate changes is only considered for the study.

The unpredictable climate change is further divided into two sub types by the village dwellers. One is 'waves and winds on the sea' seems heavy; this is called as 'rough' - 'soroppu' in traditional fishing dialogue of Tamil. However, key informant Arumugam of 65 years old explained about the nature of sea "there are many rougher waves or quite peaceful on the sea which is not meant that is all normal condition. For better fishing the sea should be seems with the small wave is good". Second sub type of unpredictable climate change is "water currents'. It may change suddenly and which impacts on fishing activities.

In general, artisanal fishermen have known and judged based on their traditional knowledge, which month is suitable for fishing and which is not good. Further, they have also known which kind of nets can be used in the particular month. Of the following information such as folk song, proverb and other village dialogue also revealed through their narratives. But they could not predict the nature of sea in a particular month based on their traditional knowledge system after the recently occurred tsunami.

The informant told "we awake up for fishing in the dawn time that differs person to person from 2 am to 5 am and come to seashore. But some time we could not lounge our boat into the sea due to the rough sea'. In some other time, the owner of fiber engine boat could engage in fishing. The small scale fishermen may join with them. That also depends on the number of person and the relationship between them. In other times, the villagers would go for fishing, when the sea seems suitable for lounging the boat. They sail their fishing boat for long far into the sea. Then the water current would suddenly be changed which is also one of the unpredictable climate changes. This kind of change also impacts on their day to day life. If their nets are damaged by getting stuck with deep sea rocks or lost with the water current, fish may not be caught on that day. Many small boats owners who have 'kattumaram' - raft boater told that, they are particularly affected by this problem than fiber engine boat's owners. 
In this juncture, the following discussions have been analysed to elucidate the problems faced by the fishermen community due to the unpredictable climate change based on empirical data.

\subsection{Consequences of Climate changes on the fishermen livelihood}

The earlier discussion on the unpredictable climate change has paved the way to analyze the major socio-economic problems faced by the fishermen community in Coromandel coastal villages due to the impact of unpredictable climate change. That is as follows:

4.2.1. Occupational uncertainty

4.2.2. Income disorganization

4.2.3. Equipments Damages and lost

4.2.4. Psycho-social problems

\subsubsection{Occupational Uncertainty}

Fishing is looked upon by the anthropologists as a kind of hunting activity because the fishermen could not determined their harvesting and many fishermen believes that fishing is a fortune. In this regards, their occupation is also considered as an uncertainty. People who are engaging for fishing that is only meant 'peasant fishermen' in this study can involve fishing activity in whole year than agricultural famers. Hence, they could not properly engage due to the unpredictable climate change. It is noted that the Government of Tamil Nadu banded 45 days for fishing activities by engine boat.

During last January - February 2013, most of the fisherfolk did not go to the sea for many days due to the sea seemed as rough. When they had been asked for the reason, many people revealed 'we could also not believes' actually sea seems at normal and all people earn a lot of money during these months. In this situation, the heads of many households are being without any earning. It is difficult to manage the bread for their daily life.

Uncertainty of fishing affects on the life of family dependents. Particularly those who are the day to day labourers in fishing and who are going to work with other boat members easily trapped into multidimensional poverty. According sample data, 25 per cent of fishing labourers are living under the poverty line.

Because, their income depends of the catching fishing that is to say, first the total income is divided into two shares, one share would be allocated for the net and boat that is for the owner, and second part of share is further divided to all members who engage in fishing by this boat. The amount of sharing income depends on the how many labourers engaged in a particular boat. In this situation the fishermen labours could not manage their family during this off season even the government has given free ration rice. Some people try to change their work into non fishing activities and some other people try to bring up their adult male children through the college education for the purpose of ensuring their work condition.

People who are working in private sectors or other types of work and parents of the male adult children who are studying in colleges were interviewed to know why do not engage in fishing and what is the reason they expense a lot of money for their male adult children's education? Regarding this question, all expression of the informants are summarized and given follows: the amount of income earning from the sea are reducing in continually after the tsunami and it is not enough to manage the day to day life with increasing coast of living.

They have no way to short out this problem because, if they like to earn a manageable income for their standard life, they should invest a lot of money to reorganize their fishing equipments and at the same time government did not also support them to get a loan. So, they have changed their occupational patterns from tradition and they try to change their children's occupational capacity. It should be noted that this kind of opportunity is delimited by their socio-economy background. This discussion also reveals the impact of climate change on the fishermen's livelihood activities.

\subsubsection{Income disorganization}

There is no notion of private property in the sea, even during the fishing season those who desire to engage in the fishing activities may involve. However the income pattern varies person to person based on their equipments, co-workers and when some fishermen may catch bulky of fishes, others come back with empty packets. One of the informants, Nadarajan of 48 years old said that, he went to sea with a type of net which can be used for catching fishes on his raft boat. But, that day the water current has changed and the prawns are caught by others. At the same time, he came back with a few fishes that were not enough for his family members. So, fishermen could not predicate their income per day. Because they could not guess sudden change of water current due to the climate change and how much fishes can be catch on a day.

Many fishermen usually come to the seashore at the dawn time. But they could not catch fish in the sea in order to the sea seems very rough. So, that whole day, their occupation is absence and they involve the plying cards and talking with others, repairing their nets damaged by the rock or some other reasons, because most of the fishermen only know to engage the fishing activities. This also affects on their day to day income patterns. 
Irregular income is one of the major impacts of climate change and it contributes to the multidimensional poverty of the village. That is to say, uncertainty of the income generates the functions of the vicious circle in the fishermen livelihood. For instances, seasonal unemployment created by the climate change leads to the income disorganization. It leads to poverty though for a short term. If this condition continues for long, the affected family is trapped by chronic poverty. It also reflects on the family particularly on children's education, health and hygiene, family psychology, and other family related problems.

\subsubsection{Damaged and lost the equipments}

Damages and loss of fishing equipments is a serious problem made by climate change. Even though, the government has provided a little support to eradicate their problem related to fishing activities after the tsunami, the village dwellers face many challenges regarding the unpredictable climate change in the whole year. Vimal of 35 years old has a small boat with only two types of net. One day, he went to sea in his small boat with his friend and threw the net for fishing. After an hour, they hauled that snared net. But they could not haul all parts of nets because the net got stuck on the deep sea rock. The reason which he told that he put the net considering the direction of water current, but the water current suddenly changed and it drew out net which plunged into the sea. If Vimal wishes to engage in fishing again, he has to buy a new set of net. For this, he should invest nearly 10,000 Indian rupees (more or less 200 dollars). It is not immediately possible because, he is a poor village dweller and his wife and two children depend on his earning. His daily income is enough only for a few days. In this situation how can he spare money for fishing equipments? The government also doesn't properly extend support for this. So, he easily becomes a fishing labourer or borrows from lenders to buy new fishing equipments. According to this case study, the impact of the climate change makes such derogatory consequences on the fishermen livelihood and leads to multi-dimensional poverty.

\subsubsection{Psycho-social problems}

The discussion described above portrays the relationship between the impact of climate change and better livelihood in the study village. This section elaborates on the psycho-social problems in relation to the impact of climate change. The term psycho-social refers to the psychological and social factors that influence mental health. Social influences such as peer pressure, parental support, cultural and religious background, socioeconomic status, and interpersonal relationships all help to shape personality and influence psychological makeup. Individuals with psychosocial disorders frequently have difficulty functioning in social situations and may have problems effectively communicating with others.

In particular stress, depression, anxiety, unnecessary angry and tension are generally correlated with occupational uncertainty, income disorganization and losing their property. Thus, unpredictable climate change contributes to new psycho-social problems among the fishermen community. Especially the person who is affected by the impact of unpredictable climate change is marginalized and could not survive within the same society. In this situation, he may become an alcohol addict. But this kind of case is minimal in the field area.

However a person, who lives alone in the seashore area, was enquired about the reason for his life alone. He told that he married and had a son (20 years old) and daughter (18 years old). But, now he has been living alone on the seashore site and prepares food himself since two years. His wife and children live at tsunami settlement and they do not talk with him. The reason for his separation could be realized by analyzing his life-history. He is indeed an alcohol addict and there are some family problems in his household because of this. So he left the home and settled on the seashore. He doesn't do any help to his family. It should be noted here that even though several factors have contributed to his present addiction to alcohol, the occupation uncertainty and its associated facts income instability are also the one of the major factors.

\section{Conclusion And Suggestions}

In this study, impact of unpredictable climate change has been assessed based on the informant case study and participant observation made in Pommaiyar Palayam traditional fishing village, Tamil Nadu, during the last six month. Based on the local people's opinion, their sustainable livelihood developmental activities have been affected by this impact of unpredictable climate change. Further, this village also was experienced and destroyed by two major cyclones during the last two year. In 2011 December, the 'thane storm' attacked this village and the 'Nilam cyclone' has also attacked the same region on November 2012, where before they relieved from Thane storm destructions. In this background, this recent study has also revealed the impacts of unpredictable climate change on the fishermen livelihood development under the four major sub issues.

The impact of climate change in fishermen livelihood development activities is clearly interpreted by the result of analysis. In this background, considering the social problems portrayed above and the discussion made with selected village key informants and peer groups, the following suggestions are proposed to promote the livelihood development in the fishing village. 
1. Conducting awareness programme to redeem them from their poverty these will include encourage them to save at least a minimum amount from their earnings. Encourage them to live a contended life with what they have.

2. In order to spend the time fruitfully they should be encouraged to occupy themselves with some form of self employment particularly off season in fishing.

3. The government should pay their attention to recover socio economic condition of families affected by the unpredictable climate change. Particularly, the government should provide necessary support to fishing labourers' families. Because, they are suffering to manage their day to day life for the reason of impact of unpredictable climate change.

4. The government should provide the compensation to person who lost their fishing equipments due to the unpredictable climate change.

5. The village dweller told that, the government doesn't provide the loan for upgrading their work condition. So the government should even arrange or provide a loan for the labourer fishermen or small boat owner to start the fishing activities individually.

\section{Acknowledgment}

I am deeply indebted to Dr. S. Bhakthavatsala Bharathi, Director of Puducherry Institute of Linguistics and Culture, Puducherry, India, my research supervisor for his constant motivation made my research and Prof.

N. Shanmugalingan, Former Vice-Chancellor, University of Jaffna, Sri Lanka, my mentor and academic guide, for his continued support in my doctoral research. I also record my sincere thanks to Dr. C. Muthumperumal, Dr. D. S. Kothari Post-Doctoral Fellow, Department of Plant Sciences, School of Biological Sciences, Madurai Kamaraj University for his meticulous help in preparing this paper and Dr. Ravisankar, Linguistics Professor for granting his support in grammatically correcting this paper. I acknowledge my sincere thanks to all my informants who have not only received me in their midst with great warmth, but showed their trust and willingness to spare freely of their invaluable time.

\section{References}

[1] M. S. Dhadave, Strategies for Rural Development in India, in. M.S. Dhadave, K.G. Joshi and S. G. Melkundi (eds.). Rural and Urban Studies in India, (New Delhi: Rawat Publications, 1996). 176 - 193

[2] S. Patnaik and J. K. Baral, Socio-Economic status of fisher Women: Continuity and Change. (New Delhi: Social Publications, 2012).

[3] M. Bavinck, Understanding Fisheries Conflicts in the South - A Legal Pluralist Perspective. Society and Natural Resources, 18 2005, 805-820.

[4] Peter Swanborn, Case Study Research: What, Why and How?. (New Delhi: Sage Publications, 2010).

[5] B. Metz, O. Davidson, R. Swart, and J. Pan, Climate Change 2001: Mitigation. (Cambridge: Cambridge University Press, 2001). 